\title{
Urban Regeneration Strategies and Place Development in Contemporary Tokyo: The Case of Shibuya Station Area
}

\section{Introduction}

Around the world, urban regeneration has become one of the key instruments in the hands of policymakers to manage urban development, improve places, and stimulate economies and investments. Previous scholarship has explored theories and practice of urban regeneration (Roberts et al., 2017; Tallon, 2013), focused on significant case studies (Balsas, 2004; Porter and Shaw, 2013; Rossi and Vanolo, 2013; Sasaki, 2010), and discussed some of the pressing issues around regeneration (Hackworth, 2007; Smith, 2012). Among these, sustainability has received much attention (Colantonio and Dixon, 2011; Lombardi et al., 2011), and sustainable development has become a quasi-ubiquitous catchphrase in policy documents and projects across the globe after being identified by the United Nation as a top priority in the international urban agenda (UN, 2016; UNWCED, 1987).

As a global city, Tokyo is no stranger to urban regeneration. On the contrary, the Japanese capital has a rich tradition of planning and policymaking that offers valuable insight into global urban phenomena. If compared to the post-war period, and similarly to other cities in Europe and North America, the Japanese authorities' approaches to urbanism in Tokyo share numerous similarities with the neoliberal urban agenda (Fujita, 2011; Sorensen, 2010; Waley, 2013). This encouraged a recent wave of urbanisation that is transforming numerous districts across the city - a trend that intensified after Tokyo was selected as the host city for the 2020 Summer Olympics in 2013. While the disruption brought by the Covid-19 pandemic over Tokyo 2020 Olympic Games casts shadows over this strategy, it is hard to deny the transformative influence of these projects on key districts of the city; an impact that is still not fully understood by scholars and policymakers alike.

This paper aims to shed light on current initiatives of urban regeneration around the Shibuya Station area in Tokyo. The objectives are twofold. One is to illustrate the characteristics of the masterplan and the planning approaches to place development framing the interventions. The other, to identify the design strategies employed to reshape the urban landscape and the public realm in the district. By doing so, the study discusses the impacts of the urban regeneration happening in Shibuya within the context of contemporary Tokyo's place development and management strategies. 
After the introduction, the paper continues with an overview of the debate surrounding urban regeneration and the planning context in Tokyo, followed by an explanation of the methodology of the study. The urban history and key features of Shibuya as a place are then illustrated. Thereafter, the paper examines the masterplan and the planning documents underpinning the ongoing regeneration, before exploring the material and immaterial features of the urban landscape produced as a result of the transformation. The concluding section summarises the characteristics of the urban regeneration of the Shibuya Station area and discusses the place development implications of the case study.

\section{Planning and urban regeneration in Tokyo}

Urban regeneration is not a new phenomenon. The idea of employing urban redevelopment to ameliorate the space and the socioeconomic trajectories of cities can be traced back to the 1950s in the context of European and North American cities suffering from early signs of industrial decline (Roberts et al., 2017; Tallon, 2013). Starting from the 1980s, and influenced by neoliberal approaches to urban governance, redevelopment initiatives show a significant turn towards entrepreneurialism with an emphasis on the private sector, market competition, place (re)branding, and flagship mega-projects (Hackworth, 2007; Hall and Hubbard, 1996; Harvey, 1989, 2005; Vanolo, 2017). At the core of these strategies was the belief that by improving the design of the urban landscape, transforming governance, and encouraging privatisation economic growth and new investments would naturally follow. From the late 1990s, and by reflecting on the impact of flagship mega-projects and their ability to catalyse area revitalisation (Doucet et al., 2011; Fainstein, 2008; Grodach, 2010), the debate around urban regeneration started to be reframed under the sustainable development paradigm-i.e. an approach to development that incorporates social, economic, and environmental sustainability (Mensah, 2019). Since then, sustainable development has become a tagline for urban regeneration initiatives. However, whether this represents a true departure from neoliberalism towards more critical and sustainable urbanism remains debatable (Lang and Rothenberg, 2017; Lombardi et al., 2011). Moreover, what sustainability means in the context of urban regeneration is still discussed and typically interventions tend to focus on providing green infrastructures or reducing cities' environmental footprints rather than transforming governance and addressing all the components of sustainability (McCormick et al., 2013).

While the pattern of neoliberal urbanism and the challenges of sustainability are by no means uniform across the world, they dramatically transformed the practice and the discourse around urban regeneration - which is now a multifaceted, ever-changing, and sophisticated global phenomenon (Leary and McCarthy, 2013). New scenarios of urban regeneration are emerging after the 2007-2008 global financial crisis, and contemporary projects attempt to transform not only spaces, but also the way they are signified, perceived, and lived. By both confronting and constructing neoliberal trends, urban 
regeneration is then revealed as 'an active practice through which the notion that all places should be seen as having to compete is lent institutional support and reinforced verbally and non-verbally by a physical environment freighted with signs' and where local circumstances and global trends intermingle (Lovering, 2007). At the same time, and notwithstanding these ambiguities, the practice of urban regeneration might support transitions towards more sustainable futures by stimulating dialogue between different stakeholders and innovation (Evans and Jones, 2008).

Recent initiatives of urban regeneration in Tokyo bear a significant resemblance to the trajectories of neoliberal urbanism. Since the late 1990s, the Japanese Government and the Tokyo Metropolitan Government (TMG) started to promote regeneration as a strategy to stimulate a stagnant economy, attract investments, and restructure the Japanese capital as a global city (Hirayama, 2017; Sassen, 2001; Waley, 2007). While planning in Tokyo still incorporates traits of the 'developmental' state ideology characterising post-war Japan (Fujita, 2003, 2011), and even though the city might lack some of the typical features found in neoliberal urbanism (Waley, 2013), the renewed attention to urban development accelerated the shift towards corporate-sector led projects and international competition.

Japanese authorities' approach to urban regeneration was utterly efficient in transforming the landscape of Tokyo in the last two decades. Large-scale redevelopment projects mostly at the scale of inner-city compounds—-such as Roppongi Hills, Shiodome, or the Marunouchi area-are a prime example (Waley, 2007). Similarly, high-rise condominiums emerged in small sites all over the city-especially in premium locations within the metropolitan area-further concentrating power and gains from redevelopment initiatives in the hands of private corporations (Hirayama, 2017; Sorensen et al., 2010). While scholarship has yet to fully analyse and understand the characteristics of the most recent initiatives of urban regeneration in Tokyo, studies found that some of them resulted in issues of gentrification (Miura, 2021), conflict (Fujii et al., 2007), and socio-spatial inequalities (Kubo, 2020); with inner areas enriching and improving their trajectories while outer suburbs are declining and shrinking (Ohashi and Phelps, 2020). Other concerns arise from the management, use, and quality criteria of privately owned public spaces (POPS) — a kind of space that is typically featured in Tokyo's redeveloped sites and offers insight into the evolving understanding of public space and place development in the Japanese capital (Cybriwsky, 1999; Dimmer, 2012).

The estimated economic gains from Tokyo 2020 Olympic Games accelerated the speed of this transformation (Lützeler, 2020; Mori, 2017), both around Olympics venues and central urban districts such as Shibuya, Shinjuku, or Shinagawa. While sustainability, renewable energies, disaster prevention and mitigation, and environmental quality feature more prominently in these projects and recent policy 


\section{Methodology}

The urban regeneration of the area around Shibuya Station has been selected as a particularly significant and timely case study in the context of recent academic debate on Japanese urbanism and place development. The area is one of the city's core districts and is located along the JR Yamanote Line, the circular line running around Tokyo's central area and connecting the city's major districts. Four railway companies converge on Shibuya Station-JR East, Tokyu Railways, Tokyo Metro, and Keio Corporation-and carry in and through the area more than 2 million passengers per day. Shibuya is a vibrant place, one of the most visited districts of the Japanese capital, and a famed epicentre of fashion, entertainment, and youth cultures. Roaming the dense network of streets that still characterise large parts of the area around the station, visitors can savour the richness and the contradiction of Tokyo's urban history. The role that the corporate sector has historically played in the development of the district adds further value to Shibuya as a case study and allows to closely observe, investigate, and foresee urban regeneration trends in the Japanese capital.

By using a case study approach, this paper combines data from historical and archival research — which is used to contextualise the ongoing transformation-and documentary sources underpinning the Shibuya Station area's current phase of urban regeneration. These include policy documents, project plans, and reports authored by both public authorities and private stakeholders; as well as articles from different 
news outlets documenting the redevelopment. Sources are available in English or Japanese-with translations of Japanese terms provided by the author when needed. Collating these different materials helped to generate rich qualitative evidence, and account for the multifaceted and ever-changing sociotechnical reality of Shibuya. Documentary sources are supplemented by extensive fieldwork undertaken between 2015 and 2019. This was instrumental to gain first-hand knowledge and record the gradual changes in the area through a variety of techniques including photos, videos, maps, and sketches. The methods employed to analyse data and produce knowledge are interpretative, iterative, and entail the researcher's positionality and reflexivity (Yanow and Schwartz-Shea, 2015). From this standpoint, the encounter with the urban field is context-specific, and each visit to Shibuya was key to discover relationships and meanings and get a better sense of the data collected over time.

\section{Placing Shibuya}

The creation and development of Shibuya — and other similar districts in Tokyo such as Shinjuku or Ikebukuro-is rooted in the urban history of the Japanese capital. As the city rapidly expanded in the aftermath of the Great Kanto Earthquake of 1923, new and mostly unplanned urban fabric started to appear in the areas located at the intersection between suburban railways and the Yamanote Line loop. The importance of these districts kept growing during and after the post-war reconstruction, when they became a cornerstone of the planning strategies devised to promote polycentrism and alleviate the concentration of functions in Tokyo's CBD (Nakabayashi, 2006; Sorensen, 2001; TMG, 1994). The work of the national government to promote urban growth by softening regulatory frameworks (Sorensen $e t$ al., 2010)—chiefly through the Urban Renaissance Special Measures Law of 2002 and its subsequent amendments—concurred to boost development around Tokyo's 'subcentres'. As a result of highly flexible land use and relaxed floor area ratios, and encouraged by TMG's strategy to achieve urban policy goals by relying on private-sector initiative and capitals (TMG, 2011), projects of large-scale urban regeneration started in numerous districts of the city.

Planning around Shibuya Station is further complicated by the network of actors operating in the area and the complexity of the place management and development processes they employ. Besides public authorities — which include the national administration, TGM, and Shibuya City — railway companies and their subsidiaries play a determinant role thanks to their historical function as urban developers in the district. This is a common feature in Japanese large metropolitan areas, Tokyo in particular, and is the result of Japanese railway companies' ability to manage a diverse portfolio of businesses to stimulate and profit from passengers' ridership and revenues - a model perfected over the years and under which the development of terminal stations and commuter-oriented districts like Shibuya is key (Calimente, 2012; Chorus and Bertolini, 2016; Saito, 1997). 
The urban development promoted by railway companies, especially Tokyu Corporation, is a prominent feature of the place identity of Shibuya — the traces of which can be found in iconic buildings in the area such as Shibuya 109, Bunkamura, Shibuya Mark City, or the old Tokyu Bunka Kaikan now replaced by Shibuya Hikarie. Major Japanese department stores, international retailers, and a variety of local businesses are also located in Shibuya - a mix that gives the district its characteristic vibrancy and cemented the reputation of Shibuya as a place for fashion and youth cultures. Although plans and interventions promoted by both private and public actors have repeatedly regenerated the district since the 1960s as a 'staged' place for consumption and urban experimentation (Morris, 2010; Yoshimi, 1987), around Shibuya Station it is still possible to find dense urban fabric characterised by pre-war street patterns, pockets of green space, independent businesses, and small residential buildings. These different urban landscapes, and the socio-technical conditions they represent, coexist not without friction and, currently, their precarious equilibrium is being renegotiated due to the pressure of the large-scale urban regeneration happening around Shibuya Station.

The combination of these forces defines Shibuya as a vital yet contradictory place. The presence of crowds, leisure, and consumption might be interpreted as an expression of Japanese place-making traditions typified by the notion of sakariba, a 'third place' in between the residence and the workplace where to gather and liberate one's identity from everyday social constraints (Cybriwsky, 1988; Linhart, 1986; Yoshimi, 1987). The increased pervasiveness of private initiative in the urban landscape, on the other hand, is representative of the 'commodification' of subjects and places produced by modernity in Tokyo (Fuji, 1999), and a sign of a progressive 'metamorphosis' of public space characterized by increasing privatization and marginalization of spontaneous and unregulated activities (Reggiani et al., 2018). By being key to determine the future of the district, the current process of urban regeneration prompts a re-examination of this conundrum that lies at the core of Shibuya's identity as a place.

\section{The redevelopment plan of the Shibuya Station area: a 'historic' opportunity for urban regeneration}

Following the designation of the Shibuya Station area as an Urban Renaissance Urgent Redevelopment Areas in December 2005 and several years of planning, a comprehensive plan of urban redevelopment for the area was approved in 2013. The project is framed by the 2010 Town Development Guidelines for Shibuya Station Central Area (Shibuya City, 2011), the Shibuya Station Area Land Readjustment Project, and the work of the different councils managed by Shibuya City to liaise among the stakeholders in the districts. The plan is also linked to a major infrastructural upgrade of Shibuya station which includes, 
among others, the redevelopment of Tokyo Metro's Ginza Line terminal, the construction of new platforms for the JR Saikyo Line, and the relocation underground of the Tokyu Toyoko Line. Jointly built by Tokyu and Tokyo Metro to directly connect Toyoko Line with Fukutoshin Line (the through service between the two was inaugurated in 2013), the new underground station made available a significant amount of land in premium locations east and south of Shibuya Station-the redevelopment of which was spearheaded, in 2012, by the opening of Shibuya Hikarie, a skyscraper of 33 floors built on the site of the old Tokyu Bunka Kaikan that existed in the area since 1961.
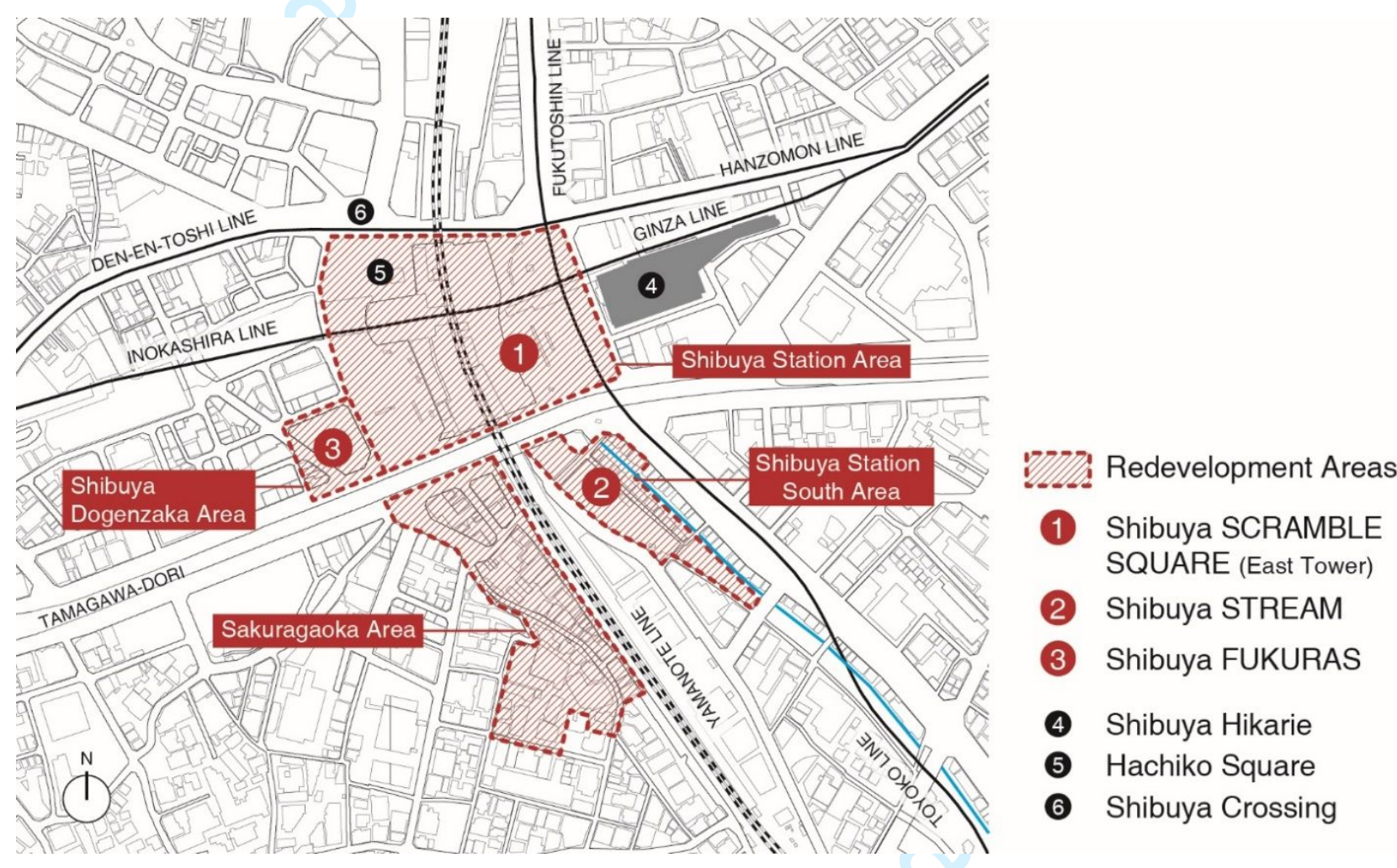

Plate 1. Map of the redevelopment areas around Shibuya Station.

The plan approved in 2013 and set to be completed by 2027 includes interventions in three zones (Plate 1). First, the Shibuya Station Area - the redevelopment of which will result in the upgrade of the railway terminal and the annexed commercial facilities. Second, the Shibuya Station South area, which includes the lands along the Shibuya River that were previously occupied by the viaduct of the Tokyu Toyoko Line. Finally, the Shibuya Dogenzaka area located west of the station on the site of the former Tokyu Plaza Shibuya (built in 1965 and finally demolished in 2015). Although it was not part of the original proposal, the plan eventually came to include also the Sakuragaoka area on the southwest of Shibuya Station. By resolving urban problems accumulated in the area, the plan aims to improve Shibuya's urban 'competitiveness' and 'appeal' while strengthening the transit node and the quality of the urban environment (Tokyu Corporation Company et al., 2013). 
The urban regeneration of Shibuya Station is key to a broader operation of place management and development. By complying with the regulations in urban regeneration special areas, public and private stakeholders joined hands in 2013 to create the Shibuya Station Area Management Council (Shibuya ekimae eria manejimento kyogi-kai) — a forum to define planning rules and the shape of the public-private cooperation. Additionally, by employing a district improvement and management approach that is increasingly popular in Japanese metropolitan areas (Yasui and Kinoshita, 2013), in 2015 they created the Shibuya Station Area Management Organisation (Ippan shadanhöjin Shibuya ekimae eria manejimento) to carry out various regeneration initiatives including extending pedestrian spaces, expanding services for visitors, or improving the energy efficiency of the area (Shibuya Station Area Management, 2020). Strategically branded as 'Shibuya +FUN Project', this operation builds on the unique reputation of Shibuya as an epicentre for fashion and creative industries and aims to posit the district as the 'best city in the world' to visit and in which to work by making Shibuya 'more exciting', 'easier to use', and safer (Shibuya Station Area Management, 2020). Key to achieving these goals is what the stakeholders describe as a sustainable mechanism for place development through which the profits generated by renting out spaces for events or surface for advertisement are reinvested into regeneration.

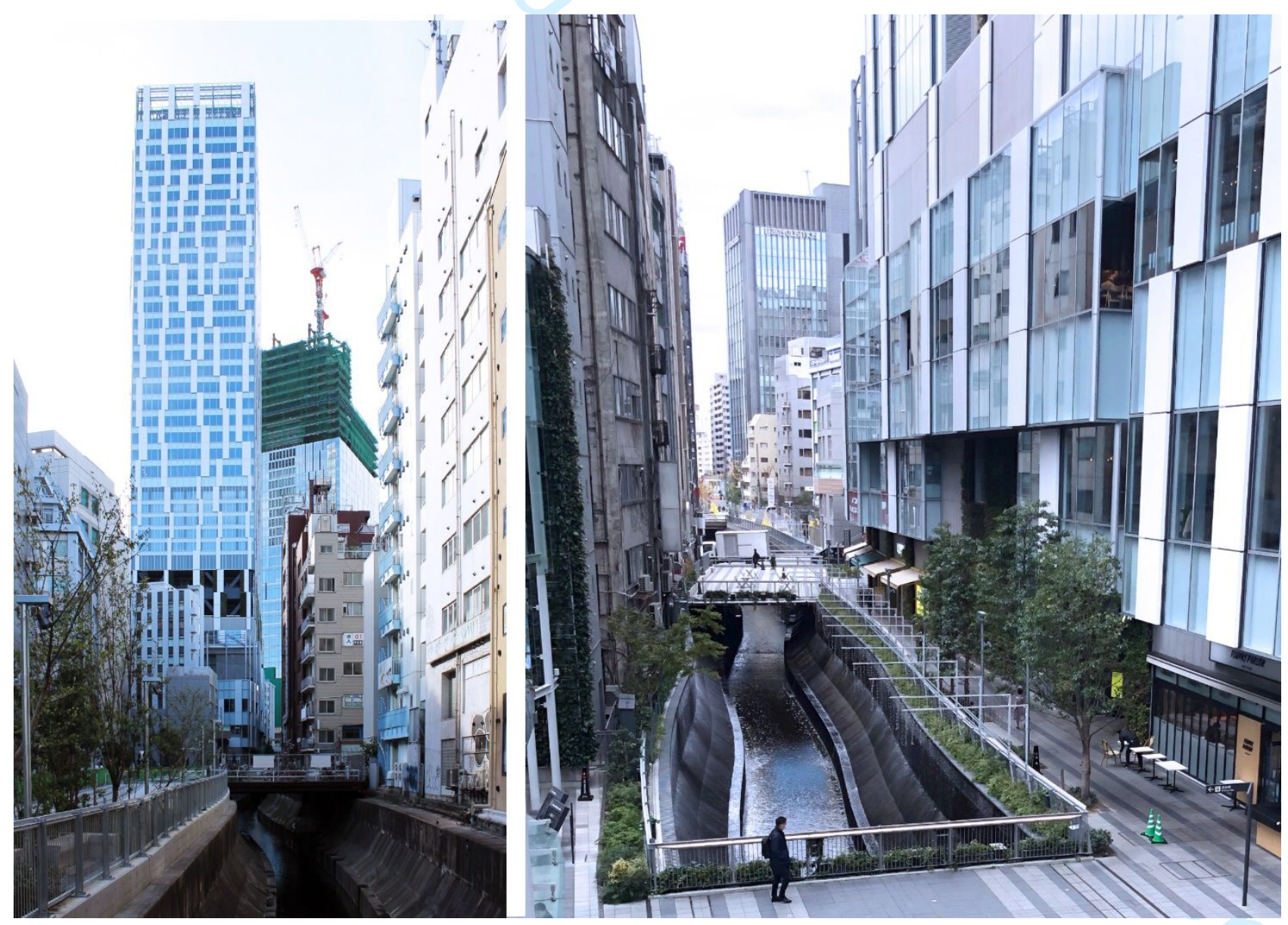

Plate 2. Shibuya Stream and the revitalisation of the Shibuya River. 
Since 2013, various projects have been completed. The first of the new buildings to be inaugurated, in September 2018, was Shibuya Stream (Plate 2). Located south of Shibuya Station, the complex is occupied by a town hall for live events and a high-rise tower of 35 floors that includes shops, restaurants, a hotel, and around 46000 sqm of flexible office space to attract workers and companies in creative fields. As the building's name suggests, the highlight of the project is the revitalisation of the portion of the Shibuya River flowing in the area. This has been accomplished by the realisation of a new waterfront, two small squares (Inaribashi and Konnoubashi Hiroba), and a green promenade (Shibuya River street) that extends towards the hills of Daikanyama—where it is connected to Shibuya Bridge, another redevelopment project recently completed in the area.

North of Shibuya Stream - to which it is connected by new pedestrian decks over Tamagawa-dori and underground passages-Shibuya Scramble Square was the next project to be completed in November 2019 (Plate 3). With 47 floors above ground and a height of about 230 metres, Shibuya Scramble Square is the new highest building in the area. The tower includes a mix of retail, restaurants, offices, and cocreation facilities to encourage creative enterprise and idea exchange (Tokyu Corporation et al., 2017). The building is topped by an observation deck (Shibuya Sky) where visitors can enjoy panoramic views over Tokyo and Mount Fuji, and experience digital art installations. Designed in collaboration with major architectural firms (Nikken Sekkei, Kengo Kuma and Associates, SANAA), Shibuya Scramble Square stands as a monumental new landmark where, as the name evokes, people can gather, explore, and consume an endless variety of goods.

Opened in December 2019, Shibuya Fukuras is one of the latest milestones from the 2013 masterplan to be accomplished. Built on the site of the old Tokyu Plaza Shibuya, this new 18-story commercial building has been conceived to embody the 'mature sensibility' and the appreciation for 'mellow' life of adult Tokyoites (Tokyu Land Corporation, 2019). Directly connected to Shibuya Station and the Sakuragaoka area with a new pedestrian deck, the building features seven floors of shops and restaurants (the new Tokyu Plaza Shibuya), plus several floors used as offices. At the ground level, Shibuya Fukauras includes a tourist information centre and a bus stop with direct services to Tokyo's airport—a service that reinforces the touristic potential of the district—whereas on floor 17 a rooftop garden (Shibu Niwa) can be accessed for free.

The transformation of the Shibuya Station area will continue in the next few years with the redevelopment of the remaining areas under construction. Planned for 2023, Shibuya Sakuragaoka will be a new residential zone provided with educational and medical facilities High-income and temporary international residents working in the area seem to be the target of this operation-a strategy that reveals 
the intention to transform Shibuya as one of the most attractive centres for global investments in Tokyo. Along with a comprehensive redesign of the famous Hachiko Square, the opening of the central and western towers within the Shibuya Scramble Square complex will finally conclude the urban regeneration process in 2027.

\section{Rescripting the urban landscape}

While the analysis of planning and policy documents illuminates the overarching aims of the plan framing the regeneration of the Shibuya Station area, evidence from the fieldwork reveals a more nuanced picture of the ongoing transformation. By focusing on the material and immaterial qualities of urban spaces and architectures produced by the urban regeneration, results are organised around five key themes: (a) densification and verticalization of the urban fabric through substitution and redevelopment of old buildings; (b) creation of high-quality, and flexible space for office, retail, and entertainment; (c) revitalisation of natural resources and design of new attractive urban spaces; (d) creation of privately owned public space; and (e) extensive renaming and rebranding of buildings and spaces in the district. These themes have been identified as they critically illustrate different and complementary facets of the redevelopment's impact on Shibuya's urban landscape and public realm.

As the projects completed by 2020 show, the process of urban regeneration has resulted in intense densification and verticalization of the built environment around Shibuya Station. The effects of this strategy are especially visible on the eastern side of the station where the three new towers of Shibuya Hikarie, Shibuya Stream, and Shibuya Scramble Square stand at a close distance. The relatively rapid creation of such impressive new landmarks has been made possible by a combination of factors which includes the availability of lands owned by Tokyu Corporation and partners, the strong cooperation between the various actors existing in the area, and the ability to replace old buildings and pre-existing urban fabric. The emphasis on iconic architectures can also be interpreted as one of the latest expressions of the constant work of planning and redevelopment promoted in Shibuya to establish the district as one of the most recognisable and competitive sub-centres in Tokyo.

The current large-scale redevelopment also represents a timely opportunity to expand and redesign the range of spaces and opportunities in the portfolio of the developers operating in Shibuya. Apart from retail, which remains a centrepiece of the projects, the new developments include a significant amount of office space to attract in the area young professionals, start-ups, and global corporations especially in the fields of media and IT. To increase the attractiveness of these spaces for Tokyo's sophisticated and global creative class, the design includes a generous amount of co-working environment that is skilfully intermingled with high-end shops, leisure, and entertainment venues. The provision of new workspace 
is complemented by the addition of new residences in the Sakuragaoka area and other "softer" forms of urban regeneration, such as the realisation of a free wi-fi network for visitors or new information spaces for tourists.
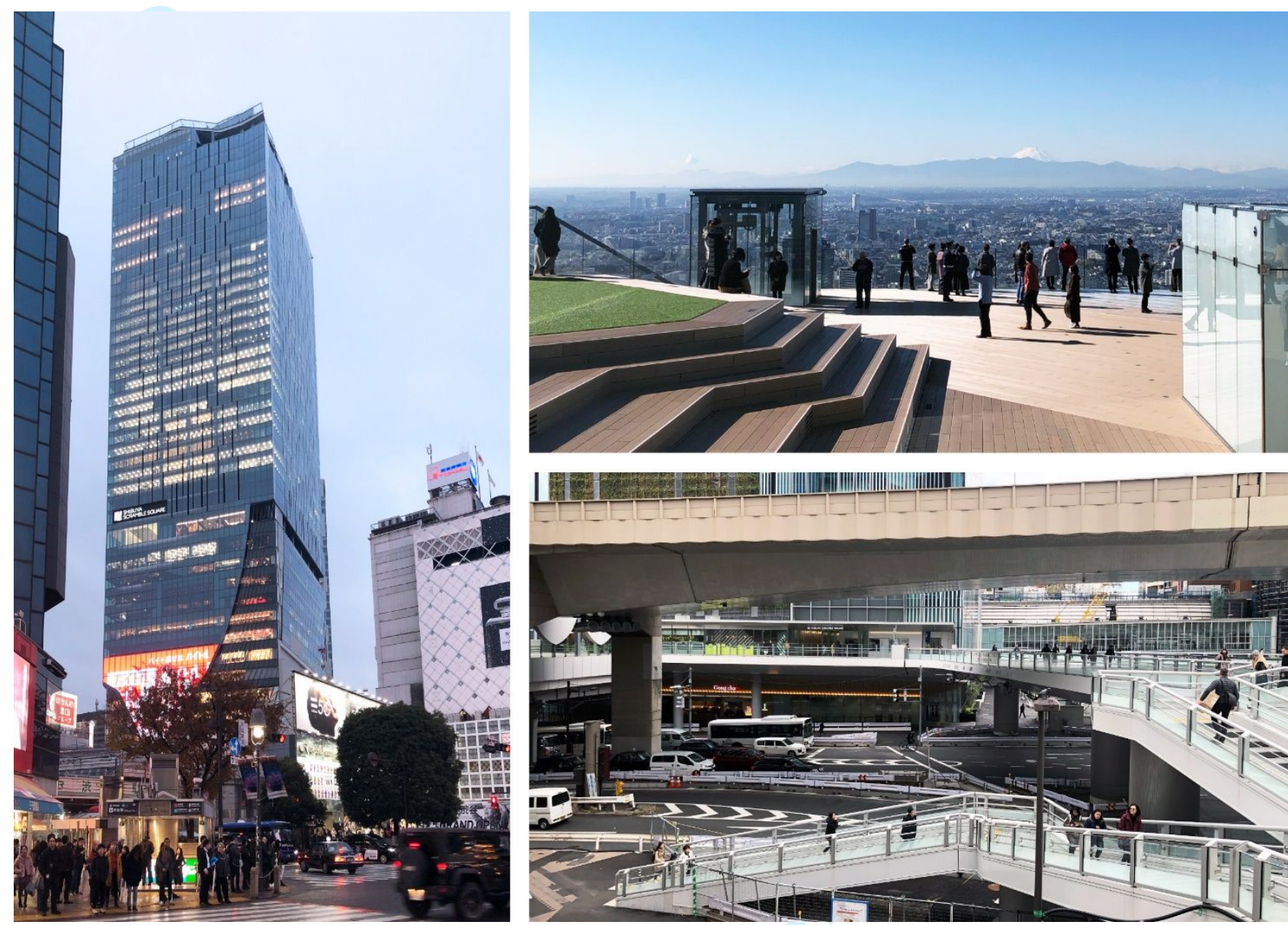

Plate 3. (left) Shibuya Scramble Square; (top) Shibuya Sky; (bottom) Multilevel POPS in the area.

If compared to previous initiatives of place development in the area, the focus on the valorisation of natural resources represents a significant turning point in terms of urban design. Nevertheless, as illustrated by the case of Shibuya Stream (Plate 2), the character of this "rediscovery" after years of neglect is rather ambiguous. On the one hand, the renaissance of the Shibuya River is the centrepiece of a new public space - a much-needed addition in an area where open space, greenery, and opportunities to sit outdoor are scarce. On the other hand, the new riverside becomes an extension of Shibuya Stream into the urban space, an attractive backdrop to channel visitors towards the shopping areas and Shibuya Station. Similarly, the rooftop observatory of Shibuya Sky creates a new hybrid landscape where mount Fuji, aerial views of Tokyo, art, leisure, and shopping are blended (Plate 3). Notably, this area requires an entrance fee, thus restricting access to this new attraction. 
A widespread renaming of buildings and spaces accompanies the regeneration of the district. Previous buildings' names around Shibuya Station usually included those of their owners; whereas now they stand as compound words that explicitly incorporate the name "Shibuya" in association with a variety of images and metaphors. These include natural features (stream), urban features (scramble square), or abstract images (light (hikarie), growth (fukuras). Particular areas within the new buildings are also branded to emphasize their uniqueness and their attractiveness, such as in the case of Shibuya Sky or Shibuya Niwa (Garden). Together with physical transformations, these names concur to rescript the district's identity and aim to evoke an atmosphere characterised by dynamic optimism where Shibuya is transformed into a comfortable urban playground for visitors, sophisticated consumers, and the creative class (Tokyu Corporation et al., 2017).

\section{Discussion and Conclusions}

To a great extent, the rapid process of urban regeneration that is transforming the Shibuya Station area seems like a success story. After less than 10 years from the approval of the redevelopment project, and although the plan is yet to be completed, the urban landscape appears visibly transformed and new urban life is thriving in the spaces created by the regeneration. This success is due to a mix of favourable circumstances, as illustrated by the analysis of policies and plans. First, the existence of a flexible and relaxed regulatory framework encouraging corporate sector-led urban regeneration. Second, the rapid availability of land for redevelopment in the area thanks to the historical presence of private railway companies acting as land developers. Finally, the collaborative strategy of area management established by the local stakeholders and their capacity to produce a clear vision for Shibuya's future. Based on results from the fieldwork, this paper also identified five key themes that summarise the various strategies employed to transform the urban landscape in the area: (a) densification and verticalization of the urban fabric through substitution and redevelopment of old buildings; (b) creation of high-quality, and flexible space for office, retail, and entertainment; (c) revitalisation of natural resources and design of new 
attractive urban spaces; (d) creation of privately owned public space; and (e) extensive renaming and rebranding of buildings and spaces in the district. The case of Shibuya is exemplary of current initiatives of urban regeneration in Tokyo, and suggests ideas to regenerate extremely dense, hyperdeveloped, and challenged districts in metropolises around the world.

The regeneration of the Shibuya Station area shows continuity with longstanding approaches to planning and development in Tokyo (Dimmer, 2012; Fujita, 2003, 2011; Hirayama, 2017; Sorensen et al., 2010; Waley, 2007, 2013) while introducing new and more sophisticated forms of area management to share ideas, create value, and coordinate the efforts of the different stakeholders involved. The attention and the recognition that the case of Shibuya has received indicate that this approach to place management and development is likely to become increasingly influential-especially in similar core districts in Japan and other East Asian countries that might share more common points with Japanese urbanism. Nevertheless, and despite the apparent success, the interventions around Shibuya Station leave some key questions unaddressed, especially when it comes to assessing sustainability and the impact of the redevelopment on the public realm. What are the consequences for Shibuya? What does the case of Shibuya tell us about the current practice of place development in Tokyo? And, more broadly, to what extent is the plan yet another manifestation of neoliberal urbanism or a step towards a more sustainable and equitable approach to urban regeneration? Given the ongoing nature of the transformation, there is no simple or conclusive answer to these questions. However, discussing the regeneration around Shibuya Station through the lens of sustainability might offer some critical insight into these issues.

Findings suggest that, among the three dimensions of sustainability, economy prevails over social and environmental considerations. Due to this, in documents and plans the term sustainability is often used as a proxy for economic viability or the ability to generate profits that could be reinvested in regeneration initiatives. Still, it is worth noting that progress has been made by planners and developers into identifying strategies to ensure better environmental sustainability in Shibuya — such as the creation of greener, safer, and more energy-efficient urban spaces and infrastructures. But this is far from a holistic approach, and attention is focused on a few interventions rather than a radical reform of the socioeconomic structures underpinning place development in Tokyo. Similarly, the committees and the events organised to consult with the public seem more geared towards gathering support than generating critical debate and address social issues through the redevelopment. As a result, and like previous studies (Lang and Rothenberg, 2017; Lombardi et al., 2011), one might argue that sustainability is not systematically addressed by the plan and is mostly used as a proxy for economic growth and urban beautification—a rhetoric that sits 
comfortably within the neoliberal urban agenda and might endanger Shibuya's urban diversity in the long term by increasing the pressure towards commodification and privatisation.

While the quality of urban regeneration in Tokyo remains high, and although progress has been made on some dimensions of sustainability, the case of Shibuya highlights some critical issues that should be addressed to improve ongoing and future initiatives of urban regeneration-such as those happening around Shinagawa, Toranomon, or Tokiwabashi. First, the tendency to concentrate new functions and investments in already extremely dense and hyperdeveloped areas. Second, the expansion of POPS and the increased ability of private actors to manage, rescript, and profit from premium urban locations-a trend that raises concern on urban inequalities in a city where the range of unmonitored and free activities allowed in the public realm is already limited (Cybriwsky, 1999; Dimmer, 2012; Havlova et al., 2018). Finally, the emphasis on economic growth and attracting new visitors-two assumptions that should be reconsidered under the light of the challenges brought by the Covid-19 pandemic and the downscaled Tokyo 2020 Olympics. As it is hard to imagine how these issues might be solved in the foreseeable future, reasonable concern remains over the long-term sustainability of planning in Tokyo and whether another crisis might befall the city's real estate market once redevelopment operations in prime sites will be completed, or in the case the ongoing projects fail to meet their targets (for example, if office demand is lower than previously anticipated).

To conclude, while the study is set in the context provided by the Japanese capital, strategies and results obtained from the analysis of the ongoing urban regeneration around Shibuya Station help to illuminate common tropes, contradictions, and inconsistencies of contemporary practices of urban regeneration around the world. As Shibuya's case suggests, while private-led initiatives prioritise growth and economic gains, more public discussion would be needed to envision inclusive instruments of place management and development that could balance competing interests. Therefore, more empirical research is required both in Japan and elsewhere to assess current strategies of urban regeneration and suggest new mechanisms to holistically address sustainability, one of the main challenges for the future of cities and regions across the globe.

\section{References}

Andrews, W. (2020), “Playful Protests and Contested Urban Space: the 2020 Tokyo Olympics Protest Movement", The Asia-Pacific Journal / Japan Focus, Vol. 18 No. 5, pp. 1-11.

Balsas, C.J.L. (2004), "City Centre Regeneration in the Context of the 2001 European Capital of Culture in Porto, Portugal", Local Economy, SAGE Publications Ltd, Vol. 19 No. 4, pp. 396-410. 
Calimente, J. (2012), "Rail integrated communities in Tokyo", Journal of Transport and Land Use, Vol. 5 No. 1, pp. 19-32.

Chorus, P. and Bertolini, L. (2016), “Developing transit-oriented corridors: Insights from Tokyo", International Journal of Sustainable Transportation, Faylor \& Francis,-Vol. 10 No. 2, pp. 86-95.

Colantonio, A. and Dixon, T. (2011), Urban Regeneration and Social Sustainability: Best Practice from European Cities, John Wiley \& Sons, New York.

Cybriwsky, R. (1988), "Shibuya Center, Tokyo", Geographical Review, [American Geographical Society, Wiley],Vol. 78 No. 1, pp. 48-61.

Cybriwsky, R. (1999), “Changing patterns of urban public space”, Cities, Vol. 16 No. 4, pp. $223-231$.

Dimmer, C. (2012), "Re- imagining public space: the vicissitudes of Japan's privately owned public spaces", in Brumann, C. and Schulz, E. (Eds.), Urban Spaces in Japan: Cultural and Social Perspectives, Routledge, London, pp. 74-105.

Doucet, B., van Kempen, R. and van Weesep, J. (2011), “'We're a Rich City with Poor People': Municipal Strategies of New-Build Gentrification in Rotterdam and Glasgow", Environment and Planning A: Economy and Space, SAGE Publications Ltd, Vol. 43 No. 6, pp. 1438-1454.

Evans, J. and Jones, P. (2008), "Rethinking Sustainable Urban Regeneration: Ambiguity, Creativity, and the Shared Territory", Environment and Planning A: Economy and Space, SAGE Publications Ltd, Vol. 40 No. 6, pp. 1416-1434.

Fainstein, S.S. (2008), "Mega-projects in New York, London and Amsterdam”, International Journal of Urban and Regional Research, Vol. 32 No. 4, pp. 768-785.

Fuji, J. (1999), “Intimate Alienation: Japanese Urban Rail and the Commodification of Urban Subjects”, Differences: A Journal of Feminist Cultural Studies, Vol. 11 No. 2, pp. 106-133.

Fujii, S., Okata, J. and Sorensen, A. (2007), "Inner-city redevelopment in Tokyo: Conflicts over urban places, planning governance, and neighborhoods", in Sorensen, A. and Funck, C. (Eds.), Living Cities in Japan: Citizens' Movements, Machizukuri and Local Environments, Routledge Taylor \& Francis Group,-Routledge, London, pp. 247-266. 
Fujita, K. (2003), "Neo-industrial Tokyo: Urban Development and Globalisation in Japan's State-centred", Vol. 40 No. 2, pp. 249-281.

Fujita, K. (2011), “Financial crises, Japan's state regime shift, and Tokyo's urban policy”, Environment and Planning A, Vol. 43 No. 2, pp. 307-327.

Grodach, C. (2010), "Beyond Bilbao: Rethinking Flagship Cultural Development and Planning in Three California Cities", Journal of Planning Education and Research, Vol. 29 No. 3, pp. 353-366.

Hackworth, J. (2007), The Neoliberal City: Governance, Ideology, and Development in American Urbanism, Cornell University Press, Ithaca, NY.

Hall, T. and Hubbard, P. (1996), "The entrepreneurial city: new urban politics, new urban geographies?", Progress in Human Geography, Vol. 20 No. 2, pp. 153-174.

Harvey, D. (1989), “From managerialism to entrepreneurialism: the transformation in urban governance in late capitalism", Geografiska Annaler. Series B, Human Geography, Vol. 71 No. 1, pp. 1-15.

Harvey, D. (2005), A Brief History of Neoliberalism, Oxford University Press, Oxford.

Havlova, Z., Siqi, L., Ikalovic, V., Reggiani, M. and Wu, Z. (2018), "Public space for sedentary activities in Tokyo: Unnecessary and undesired luxury?", UA 城市建筑- Urbanism and Architecture, Vol. 2018 No. 18 , pp. $108-118$.

Hirayama, Y. (2017), "Selling the Tokyo Sky: Urban Regeneration and Luxury Housing", in Forrest, R., Koh, S.Y. and Wissink, B. (Eds.), Cities and the Super-Rich: Real Estate, Elite Practices and Urban Political Economies, Palgrave Macmillan, New York, pp. 189-208.

Kubo, T. (2020), Divided Tokyo: Disparities in Living Conditions in the City Center and the Shrinking Suburbs, Springer Singapore.

Lang, S. and Rothenberg, J. (2017), "Neoliberal urbanism, public space, and the greening of the growth machine: New York City's High Line park", Environment and Planning A: Economy and Space, Vol. 49 No. 8, pp. 1743-1761.

Leary, M.E. and McCarthy, J. (Eds.). (2013), The Routledge Companion to Urban Regeneration, Routledge, New York. 
Lin, Z. (2018), “Ecological urbanism in East Asia: A comparative assessment of two eco-cities in Japan and China", Landscape and Urban Planning, Vol. 179, pp. 90-102.

Linhart, S. (1986), “Sakariba: Zone of 'Evaporation' between Work and Home?”, in Hendry, J. and Webber, J. (Eds.), Interpreting Japanese Society: Anthropological Approaches, JASO, Oxford, pp. $198-210$. Lombardi, R.D., Porter, L., Barber, A. and Rogers, C.D.F. (2011), “Conceptualising Sustainability in UK Urban Regeneration: a Discursive Formation", Urban Studies, Vol. 48 No. 2, pp. 273-296.

Lovering, J. (2007), “The Relationship Between Urban Regeneration and Neoliberalism: Two Presumptuous Theories and a Research Agenda", International Planning Studies, Vol. 12 No. 4, pp. 343-366.

Lützeler, R. (2020), “Tokyo 2020 and neighborhood transformation: Reworking the entrepreneurial city”, in Holthus, B., Gagné, I., Manzenreiter, W. and Waldenberger, F. (Eds.), Japan Through the Lens of the Tokyo Olympics, Routledge, London, pp. 39-45.

McCormick, K., Anderberg, S., Coenen, L. and Neij, L. (2013), “Advancing sustainable urban transformation”, Journal of Cleaner Production, Vol. 50, pp. 1-11.

Mensah, J. (2019), "Sustainable development: Meaning, history, principles, pillars, and implications for human action: Literature review", Cogent Social Sciences, Vol. 5 No. 1, p. 1653531.

Miura, R. (2021), "Rethinking Gentrification and the Right to the City: The Process and Effect of the Urban Social Movement against Redevelopment in Tokyo", International Journal of Japanese Sociology, Vol. 30 No. 1, pp. 64-79.

Mori, C. (2017), "Social Housing and Urban Renewal in Tokyo: From Post-War Reconstruction to the 2020 Olympic Games", in Watt, P. and Smets, P. (Eds.), Social Housing and Urban Renewal, Emerald Publishing, Bingley, pp. 277-309.

Morris, B. (2010), “Un/Wrapping Shibuya: Place, Media, and Punctualization”, Space and Culture, Vol. 13 No. 3, pp. 285-303.

Nakabayashi, I. (2006), “Concentration and deconcentration in the context of the Tokyo Capital Region Plan and recent cross-border networking concepts", in Hein, C. and Pelletier, P. (Eds.), Cities, Autonomy, and Decentralization in Japan, Routledge, London, pp. 55-80. 
Ohashi, H. and Phelps, N.A. (2020), "Diversity in decline: The changing suburban fortunes of Tokyo Metropolis", Cities, Vol. 103, p. 102693.

Ortiz-Moya, F. (2020), “Green growth strategies in a shrinking city: Tackling urban revitalization through environmental justice in Kitakyushu City, Japan", Journal of Urban Affairs, Routledge, Vol. 42 No. 3, pp. 312-332.

Porter, L. and Shaw, K. (2013), Whose Urban Renaissance?: An International Comparison of Urban Regeneration Strategies, Routledge, London.

Reggiani, M., Wu, Z., Li, S., Havlova, Z. and Ikalovic, V. (2018), “The Metamorphosis of Contemporary Public Space: The Role of Informal Buffer Zones in Shinjuku Area, Tokyo", UA 城市建筑- Urbanism and Architecture, Vol. 2018 No. 10, pp. 26-34.

Roberts, P., Sykes, H. and Granger, R. (2017), Urban Regeneration, 2nd ed., Sage, London.

Rossi, U. and Vanolo, A. (2013), "Regenerating what? The politics and geographies of actually existing regeneration", in Leary, M.E. and McCarthy, J. (Eds.), The Routledge Companion to Urban Regeneration, Routledge, New York.

Saito, T. (1997), “Japanese Private Railway Companies and Their Business Diversification”, Japan Railway \& Transport Review, No. 10, pp. 2-9.

Sasaki, M. (2010), "Urban regeneration through cultural creativity and social inclusion: Rethinking creative city theory through a Japanese case study", Cities, Vol. 27, pp. S3-S9.

Sassen, Saskia. (2001), The Global City: New York, London, Tokyo, Princeton University Press, Princeton. Shibuya City. (2011), Shibuya-eki chūshin chiku-ku machi-dzukuri shishin 2010 [2010 Town Development Guidelines for Shibuya Station Central Area], Shibuya City, available at: https://www.city.shibuya.tokyo.jp/kankyo/machi/shibuya_eki/shibuya_shishin.html (accessed 20 April 2021).

Shibuya Station Area Management. (2020), Shibuya Area Management Activity Report 2013-2020, available at: https://shibuyaplusfun.com/docs/activityreport_2013_2020_01.pdf (accessed 2 August 2021). Smith, A. (2012), Events and Urban Regeneration: The Strategic Use of Events to Revitalise Cities, Routledge, London. 
Sorensen, A. (2001), “Subcentres and satellite cities: Tokyo's 20th century experience of planned polycentrism", International Planning Studies, Vol. 6 No. 1, pp. 9-32.

Sorensen, A. (2010), "Urban Sustainability and Compact Cities Ideas in Japan: The diffusion, transformation and deployment of planning concepts", in Healey, P. and Upton, R. (Eds.), Crossing Borders: International Exchange and Planning Practices, Routledge, London, pp. 117-140.

Sorensen, A., Okata, J. and Fujii, S. (2010), “Urban Renaissance as Intensification : Building Regulation and the Rescaling of Place Governance in Tokyo's High-rise Manshon Boom”, Vol. 47 No. March, pp. $556-583$.

Tallon, A. (2013), Urban Regeneration in the UK, 2nd Edition., Routledge, London.

TMG (Ed.). (1994), A Hundred Years of Tokyo City Planning, Tokyo Metropolitan Government, Tokyo, Japan. TMG. (2011), Urban Development in Tokyo, Bureau of Urban Development Tokyo Metropolitan Government, Tokyo, available at: https://www.toshiseibi.metro.tokyo.lg.jp/pamphlet/pdf/udt2011english.pdf (accessed 2 August 2021).

TMG. (2020), Creating a Sustainable City. Tokyo's Environmental Policy, Tokyo Metropolitan Government, available at: https://www.metro.tokyo.lg.jp/english/about/environmental_policy/index.html (accessed 2 August 2021).

Tokyu Corporation Company, East Japan Railway Company, and Tokyo Metro. (2013), Urban Planning Proposal for Areas Surrounding Shibuya Station (Plan), Tokyo, Japan, available at: https://www.tokyu.co.jp/ir/upload_file/ENtop_01/9005_2013032817342804_P01_.pdf (accessed 20 April 2021).

Tokyu Corporation, East Japan Railway Company, and Tokyo Metro. (2017), Shibuya-Eki Gaiku Kaihatsu Keikaku No Shisetsu Meishō Ga 'Shibuya Sukuranburusukuea' Ni Kettei ['Shibuya Scramble Square' Has Been Decided as the Name of the Shibuya Station Block], Tokyo, Japan, available at: https://www.tokyu.co.jp/file/170801.pdf (accessed 20 April 2021).

Tokyu Land Corporation. (2019), Tokyu Land Corporation. Company Guide 2019-2020, Tokyu Land Corporation, Tokyo. 
United Nations (UN). (2016), The Sustainable Development Goals Report, United Nations, New York, NY.

United Nations World and Commission on Environment and Development (UNWCED). (1987), Our Common Future (The Brundtland Report), Oxford University Press, Oxford.

Vanolo, A. (2017), City Branding: The Ghostly Politics of Representation in Globalising Cities, Routledge, New York.

Waley, P. (2007), "Tokyo-as-World-City: Reassessing the Role of Capital and the State in Urban Restructuring", Urban Studies, Vol. 44 No. 8, pp. 1465-1490.

Waley, P. (2013), "Pencilling Tokyo into the map of neoliberal urbanism”, Cities, Elsevier Ltd, Vol. 32, pp. 43-50.

Yanow, D. and Schwartz-Shea, P. (2015), Interpretation and Method: Empirical Research Methods and the Interpretive Turn, Routledge, New York.

Yasui, M. and Kinoshita, H. (2013), “Challenges in district management in Japanese city centres: Establishing independent business models using local resources", Journal of Urban Regeneration \& Renewal, Vol. 6 No. 3, pp. 264-277.

Yoshimi, S. (1987), Toshi no doramaturugi: Tokyo sakariba no shakaishi [The Dramaturgy of the City: The Social History of Tokyo Entertainment Districts], Kōbundō, Tokyo. 